OPEN ACCESS

Edited by:

Giacinto Bagetta,

University of Calabria, Italy

Reviewed by:

Thomas Heinbockel,

Howard University, United States Marco Cosentino,

University of Insubria, Italy

*Correspondence:

Yi-Hung Chen

yihungchen@mail.cmu.edu.tw

Specialty section:

This article was submitted to

Neuropharmacology,

a section of the journal

Frontiers in Neuroscience

Received: 12 August 2020 Accepted: 23 December 2020 Published: 18 February 2021

Citation:

MacDonald IJ and Chen Y-H (2021) The Endocannabinoid System Contributes to Electroacupuncture

Analgesia.

Front. Neurosci. 14:594219. doi: 10.3389/fnins.2020.594219

\section{The Endocannabinoid System Contributes to Electroacupuncture Analgesia}

\author{
Iona J. MacDonald ${ }^{1}$ and Yi-Hung Chen ${ }^{1,2,3 *}$ \\ ${ }^{1}$ Graduate Institute of Acupuncture Science, China Medical University, Taichung, Taiwan, ${ }^{2}$ Chinese Medicine Research \\ Center, China Medical University, Taichung, Taiwan, ${ }^{3}$ Department of Photonics and Communication Engineering, Asia \\ University, Taichung, Taiwan
}

The extensive involvement of the endocannabinoid system (ECS) in vital physiological and cognitive processes of the human body has inspired many investigations into the role of the ECS and drugs, and therapies that target this system and its receptors. Activation of cannabinoid receptors 1 and $2\left(\mathrm{CB}_{1}\right.$ and $\left.\mathrm{CB}_{2}\right)$ by cannabinoid treatments, including synthetic cannabinoids, alleviates behavioral responses to inflammatory and neuropathic pain. An increasing body of scientific evidence details how electroacupuncture (EA) treatments achieve effective analgesia and reduce inflammation by modulating cannabinoid signaling, without the adverse effects resulting from synthetic cannabinoid administration. $\mathrm{CB}_{1}$ receptors in the ventrolateral area of the periaqueductal gray are critically important for the mechanisms of the EA antinociceptive effect, while peripheral $\mathrm{CB}_{2}$ receptors are related to the anti-inflammatory effects of $E A$. This review explores the evidence detailing the endocannabinoid mechanisms involved in EA antinociception.

Keywords: cannabinoid receptors, electroacupuncture, endocannabinoid system, analgesia, pain

\section{INTRODUCTION}

Since its discovery in the 1990s, the complex signaling network of the endocannabinoid system (ECS) has increasingly been seen to be a key player in the regulation of numerous vital physiological and cognitive processes, such as female reproductive events, pain sensation, mood, and in mediating the pharmacological effects of cannabis (Wang et al., 2006; McPartland et al., 2007; Aizpurua-Olaizola et al., 2017; Toth et al., 2019).

The ECS contains two major G-protein-coupled type $1\left(\mathrm{CB}_{1}\right)$ and type $2\left(\mathrm{CB}_{2}\right)$ cannabinoid receptors that are activated by the psychoactive ingredient of cannabis, $\Delta^{9}$-tetrahydrocannabinol (THC). The main basic mechanisms triggered by $\mathrm{CB}_{1}$ and $\mathrm{CB}_{2}$ receptors are mediated by $\mathrm{G}$ proteins that are mostly of the $\mathrm{G}_{\mathrm{i} / \mathrm{o}}$ type, resulting in inhibition of activity of adenylate cyclases, the cAMP cascade and voltage-gated calcium $\left(\mathrm{Ca}^{2+}\right)$ channels, and stimulation of mitogen-activated protein kinase (MAPK) activity (Di Marzo and Petrocellis, 2006). $\mathrm{CB}_{1}$ receptors also inhibit voltage-activated $\mathrm{Ca}^{2+}$ channels, stimulate inwardly rectifying potassium $\left(\mathrm{K}^{+}\right)$ currents and activate both phospholipase C (through G protein $\beta \gamma$ subunits) and PI-3-kinase (Di Marzo and Petrocellis, 2006). 
$\mathrm{CB}_{1}$ is mainly expressed in the cerebral cortex, basal ganglia, cerebellum, and hippocampus; lower levels of $\mathrm{CB}_{1}$ expression are found in the peripheral and autonomic nervous system, as well as the heart, lung, thymus, spleen, and reproductive system (Fulmer and Thewke, 2018). $\mathrm{CB}_{1}$ is also expressed in immune cells, at levels of up to 100-fold lower than those of $\mathrm{CB}_{2}$ (Fulmer and Thewke, 2018). In the central nervous system (CNS), activation of $\mathrm{CB}_{1}$ inhibits excitatory and inhibitory neurotransmission, and the modulation of cognitive, memory, and motor functions, as well as analgesia (Chiurchiu et al., 2015).

$\mathrm{CB}_{2}$ is expressed predominantly by cells of hematopoietic origin in the peripheral immune system (in bones, spleen, and skin); low levels of $\mathrm{CB}_{2}$ expression are found in other cell types, including epithelial cells, osteogenic cells, cardiomyocytes, fibroblasts, and vascular smooth muscle cells (Fulmer and Thewke, 2018). Evidence of $\mathrm{CB}_{2}$ expression in the CNS is controversial and requires further confirmation (Fulmer and Thewke, 2018). Upregulation of $\mathrm{CB}_{2}$ is implicated in chronic inflammation of the nervous system, as well as with several cardiovascular and bone disorders (Chiurchiu et al., 2015).

Two endogenous lipophilic molecules, anandamide (AEA, $\mathrm{N}$-arachidonoylethanolamide) and 2-arachidonoylglycerol (2-AG), are capable of activating $\mathrm{CB}_{1}$ and $\mathrm{CB}_{2}$, and are considered to be the main endocannabinoids (Aizpurua-Olaizola et al., 2017; Maccarrone, 2017). These endocannabinoids, as well as various enzymes involved in the biosynthesis and/or degradation of endogenous lipid ligands, comprise the ECS, a complex enzyme and transporter apparatus that affects virtually all central and peripheral systems in mammals (Aizpurua-Olaizola et al., 2017; Toth et al., 2019). With ongoing research identifying more bioactive lipids with cannabimimetic properties, it is reasonable to expect that investigations will gradually offer more insights into the ECS (Aizpurua-Olaizola et al., 2017; Maccarrone, 2017; Toth et al., 2019).

\section{TARGETING THE ENDOCANNABINOID SYSTEM (ECS) FOR TREATING PAIN AND INFLAMMATION}

The involvement of the ECS in several physiological regulation pathways makes it an attractive target for drugs and therapies in the management of pain and inflammation. Activation of endocannabinoids alleviates behavioral responses to acute, inflammatory and neuropathic pain (Palazzo et al., 2010). The $\mathrm{CB}_{1}$ receptor is found in high densities in the superficial layers of the spinal dorsal horn $(\mathrm{SDH})$, the dorsal root ganglia, the descending pathway of pain modulation, and the peripheral terminals of primary afferent neurons (Palazzo et al., 2010). The cellular location of $\mathrm{CB}_{1}$ receptors is predominantly the presynaptic axon terminals of both $\gamma$ aminobutyric acid (GABA)ergic, and glutamatergic neurons (Campolongo and Fattore, 2015). Smaller quantities of $\mathrm{CB}_{1}$ receptors are expressed in astrocytes, oligodendrocytes, and microglia, where the receptors regulate synaptic transmission (Zou and Kumar, 2018). $\mathrm{CB}_{2}$ receptors predominantly reside in the periphery and represent a target in inflammatory pain processing (Palazzo et al., 2010).

AEA and 2-AG are synthesized on demand and function as retrograde messengers after their release from postsynaptic neurons in areas related to the descending pain modulatory pathway, from where they are transported to the CNS and peripheral terminals of primary afferent neurons, inhibiting neurotransmitter release from presynaptic terminals (Gondim et al., 2012; Kano, 2014). By activating $\mathrm{CB}_{1}$ receptors in astrocytes, 2-AG triggers the release of glutamate, which activates the $N$-methyl-D-aspartate receptor (NMDAR) on pyramidal neurons (Zou and Kumar, 2018). Dense populations of endocannabinoid signaling molecules surround synapses in various brain regions including the periaqueductal gray (PAG) region, the hippocampus, cerebral cortex, amygdala, dorsal and ventral striatum, hypothalamus, cerebellum, and spinal cord, all of which are considered to be responsible for the neural functions that depend upon endocannabinoid signaling (Kano, 2014). Experimental data show that retrograde endocannabinoid signaling governs various aspects of neural signaling including learning and memory, anxiety and mood, addiction, feeding behavior, motor learning, and analgesia (Kano, 2014). Activation of $\mathrm{CB}_{1}$ and $\mathrm{CB}_{2}$ receptors inhibits established inflammatory hypersensitivity and swelling in animal models of inflammatory hyperalgesia (Gondim et al., 2012). Human samples of osteoarthritis and rheumatoid arthritis synovium tissue contain $\mathrm{CB}_{1}$ and $\mathrm{CB}_{2}$ receptors as well as $\mathrm{AEA}$ and 2$A G$, indicating that the ECS may be closely related to pain and inflammation associated with arthritic disease (Gondim et al., 2012).

Cannabinoid treatments have proven efficacy in chronic pain and symptom control in palliative/supportive care. These compounds include the plant-derived cannabinoid tetrahydrocannabinol/cannabidiol (THC/CBD) oromucosal spray (nabiximols), and the synthetic THC analogs nabilone, dronabinol, and ajulemic acid, as well as the CBD oral solution Epidiolex ${ }^{\circledast}$, all of which achieve their biological effects by activating cannabinoid receptors. However, while synthetic cannabinoids are generally devoid of many of the side effects of opiates, such as their large abuse potential and the life-threatening side effect of respiratory depression, use of synthetic cannabinoids has been linked to severe illness, intensive care admission, and death (Kasper et al., 2015). Synthetic cannabinoids can also affect the cardiovascular system, with case reports describing adverse outcomes including cardiogenic shock, acute respiratory depression and cardiopulmonary resuscitation (Khan S. P. et al., 2019).

The ECS maintains bodily homeostasis by influencing physiological processes such as cannabinoid signaling in the skin (Toth et al., 2019), emotional stasis (Stampanoni Bassi et al., 2018), immune homeostasis in the gut (Acharya et al., 2017), and the regulation of appetite, food intake, and energy balance (Pagotto et al., 2006), all of which depend on $\mathrm{CB}_{1}$ and $\mathrm{CB}_{2}$ receptors, among others (Maccarrone, 2017). The present review provides a brief general overview of 
acupuncture and electroacupuncture (EA) and highlights the therapeutic potential in EA-induced modulation of cannabinoid signaling for effective analgesia and reductions in inflammation. Importantly, these therapeutic outcomes are produced without the adverse effects associated with synthetic cannabinoids.

\section{MANUAL ACUPUNCTURE AND ELECTROACUPUNCTURE ANALGESIA}

Traditional manual acupuncture has a long history, whereas EA was introduced into clinical practice as recently as the 1950s (Napadow et al., 2005; White et al., 2008). During manual acupuncture, needles are inserted into historically and empirically defined acupoint locations and are then manually manipulated by twisting, lifting or thrusting movements (Napadow et al., 2005). The EA technique involves the insertion of two needles that serve as electrodes for passing an electric current (Napadow et al., 2005). At least one of the needles is positioned at an acupoint (Napadow et al., 2005).

Both manual acupuncture and EA have demonstrated clinically relevant effects in chronic pain conditions (Scharf et al., 2006; Endres et al., 2007; Haake et al., 2007; Selfe and Taylor, 2008; Chen et al., 2017). The use of acupuncture within TCM is supported by a wealth of data demonstrating its therapeutic effects in numerous clinical conditions, including pain, such as the treatment of general chronic pain (Vickers et al., 2012), migraine prophylaxis (Linde et al., 2016; Musil et al., 2018) and treatment (Zhao et al., 2005), the treatment of chronic low back pain (Yuan et al., 2008; Chou et al., 2017), fibromyalgia (Deare et al., 2013; Mist and Jones, 2018), and osteoarthritis (Manheimer et al., 2010; Lin et al., 2016). An individual patient data metaanalysis that used data from 29 randomized controlled trials (RCTs) including a total of 17,922 patients found that acupuncture (whether it was manual acupuncture or EA) was significantly superior to both sham and no acupuncture control for all four chronic pain conditions investigated (back and neck pain, shoulder pain, chronic headache, and osteoarthritis) for the efficacy of acupuncture (Vickers et al., 2012). These findings were confirmed in a subsequent update of this meta-analysis (Vickers et al., 2018). The updated review included an additional 13 RCTs of acupuncture (manual acupuncture or EA) compared with either sham acupuncture or no acupuncture control for non-specific musculoskeletal pain, shoulder pain, chronic headache, or osteoarthritis; data were analyzed from a total of 20,827 patients (Vickers et al., 2018).

Manual acupuncture is associated with the activation of all types of afferent fibers $(\mathrm{A} \beta, \mathrm{A} \delta$, and $\mathrm{C})$, while the EA current has to be sufficiently intense to excite $A \beta$ type and some of the A $\delta$-type afferent fibers for eliciting analgesia (Zhao, 2008). Adding manipulation to EA reportedly produces more potent analgesia compared with EA alone (Kim et al., 2000). An oft-stated advantage of EA for clinical practice or research is that it can objectively and quantifiably define stimulus frequency and intensity (Napadow et al., 2005). Functional magnetic resonance imaging (fMRI) investigations have revealed that EA (2 and $100 \mathrm{~Hz}$ ) is associated with more widespread increases in fMRI signaling compared with manual acupuncture, while all acupuncture needling is associated with more widespread responses in the brain compared with the placebo-like tactile control stimulation (Napadow et al., 2005). Differential brain activation is observed between manual acupuncture and EA, which has also been noted by other fMRI and positron emission tomography (PET) investigations into acupuncture analgesia in the human brain, suggesting that different brain networks or different brain mechanisms are involved during manual acupuncture and EA (Kong et al., 2002; Napadow et al., 2005; Yang J. et al., 2012).

Electroacupuncture (EA) is used by traditional Chinese medicine (TCM) practitioners and acupuncturists for many different therapeutic conditions (Sidhu et al., 2017). Some acupuncturists contend that manual needling is sufficient to achieve the desired therapeutic results, whereas others argue that EA provides a unique role, especially in patients with chronic nociceptive pain (White et al., 2008). Some research suggests that EA may provide more effective pain relief than manual acupuncture, with the addition of the electric current optimizing the effects elicited by manual acupuncture (Wan et al., 2001; Barlas et al., 2006). Furthermore, lowfrequency, high-intensity EA has been associated with a significantly larger hypoalgesic effect compared with placebo needling, whereas low-intensity stimulation was not significantly different from placebo needling in hypoalgesic responses (Barlas et al., 2006).

\section{THE DESCENDING PAIN MODULATORY PATHWAY IN ACUPUNCTURE ANALGESIA}

The pathophysiology of pain has been thoroughly researched by many in-depth papers and reviews (Loeser and Melzack, 1999; Raffaeli and Arnaudo, 2017; Chen et al., 2020). Among the brain and spinal cord areas, the descending pain modulatory pathway is critical in pain perception and acupuncture analgesia (Lv et al., 2019). This system arises in the PAG, where transmitters are activated that contact the rostroventromedial medulla and project to the raphe nuclei in the brainstem, and to inhibitory synapses in the SDH (Lai et al., 2019; Lv et al., 2019). Local administration of GABA agonists into the ventrolateral area of the PAG (vlPAG) promotes pain, while local administration of GABA antagonists produces antinociceptive effects by reducing inhibitory neurotransmission (Zhu et al., 2019). The GABA disinhibition hypothesis proposes that tonically active GABAergic interneurons within the PAG release $\mathrm{GABA}$, which acts via $\mathrm{GABA}_{\mathrm{A}}$ receptors to inhibit spinally projecting output neurons (Zhu et al., 2019). According to this hypothesis, opioids and cannabinoids indirectly suppress the inhibitory influence of local GABAergic interneurons and effectively disinhibit the antinociceptive pathway of the 
neuronal output descending to the spinal cord (Zhu et al., 2019). Thus, cannabinoids are capable of producing analgesia via a central action in the descending pain modulatory pathway, direct spinal action, or peripheral nerve action (Gondim et al., 2012).

\section{EXPLORATIONS INTO ACUPUNCTURE- AND ELECTROACUPUNCTURE (EA)-INDUCED ANALGESIA}

\section{Endogenous Opioid Involvement}

In 1973, Chinese investigators performed a clinical study involving healthy volunteers that demonstrated time-dependent analgesic effects of manual acupuncture at acupoint LI4 (Research Group of Acupuncture Anesthesia, 1973). The increase in pain threshold after manual acupuncture at LI4 was blocked by pretreatment with local anesthetic $2 \%$ procaine injected deep below LI4, indicating the importance of nerve innervations embedded in structures deep below the acupoint (Research Group of Acupuncture Anesthesia, 1973). When they then treated the affected limbs of hemiplegic and paraplegic patients with acupuncture, the researchers found no effect on pain threshold on the unaffected side, supporting the involvement of peripheral sensory nerves and the afferent nerve pathway in the spinal cord (Research Group of Acupuncture Anesthesia, 1973). The significance of pain relief achieved with the use of LI4 has been highlighted by recent investigations showing immediate, significant relief from inflammatory pain in mice injected with complete Freund's adjuvant (CFA) in the hind paws (Yen et al., 2019).

In the late 1970s, researchers discovered that the opiate receptor antagonist naloxone attenuated acupuncture analgesia in humans (Mayer et al., 1977) and in mice (Pomeranz and Chiu, 1976). This analgesic action was attributed to the release of a morphine-like substrate in the CNS. In the early 1980s, the purification of $\beta$-endorphin and enkephalin implicated these opiates as key players in acupuncture in humans and animals (Clement-Jones et al., 1980; Pert et al., 1981; Kiser et al., 1983). The research revealed that acupuncture increased levels of plasma enkephalin and cerebrospinal fluid $\beta$-endorphin in humans after acupuncture treatment.

Investigations into the relationship between different levels of EA analgesia have found that met-enkephalin, $\beta$-endorphin, and endomorphin are preferably stimulated by low-frequency $(2 \mathrm{~Hz}) \mathrm{EA}$, while dynorphin is the only opioid peptide that responds to high-frequency $(100 \mathrm{~Hz}) \mathrm{EA}$ stimulation (Han, 2004). Further experimental research has shown that a dense-anddisperse (DD) mode of EA stimulation alternating $2 \mathrm{~Hz}$ with $100 \mathrm{~Hz}$, each lasting for $3 \mathrm{~s}$, evokes the simultaneous release of both enkephalins and dynorphins, resulting in a synergistic interaction that maximizes the therapeutic effect (Han, 2004). These findings have been substantiated in clinical research (Han, 2011).

\section{Interference With the Central Sensitization Process}

The general consensus among scientists in the pain research field is that chronic pain states in humans are driven by three core mechanisms: nociceptive and neuropathic pain mechanisms, as well as central sensitization (Harte et al., 2018). The term central sensitization conveys the understanding that CNS mechanisms are implicated in the amplification of pain, independently of peripheral injury or inflammation (Harte et al., 2018). Effective pain management relies upon the recognition of central sensitization and whether it is resulting from ongoing nociceptive input or is occurring despite no obvious peripheral driver (Harte et al., 2018).

The analgesic effects of manual acupuncture and EA are produced through multiple pathways and interfere with the central sensitization process by reducing levels of inflammatory mediators in the peripheral tissue, including substance $\mathrm{P}$, interleukin (IL)-1 $\beta$, IL-8, IL-10, and tumor necrosis factor (TNF)- $\alpha$ (Zhang et al., 2012; Lai et al., 2019). Possible processes whereby acupuncture reduces central sensitization include the release of the endogenous opioid, adrenergic, and 5-hydroxytryptamine (5-HT, serotonin) receptors, the $N$-methyl-D-aspartate/ $\alpha$-amino-3-hydroxy-5methyl-4-isozazolepropionin acid/kainate (NMDA/AMPA/KA) pathways, and afferent segmental inhibition (Lai et al., 2019). Segmental acupuncture analgesia postulates that high-frequency, low-intensity EA activates myelinated afferent A-fibers that reduce nociceptive transmission via inhibitory interneurons in the spinal dorsal root, reducing the response to painful stimuli within the same spinal segment (Baeumler et al., 2014, 2019).

\section{The Role of the Adenosine $A_{1}$ Receptor}

Researchers have noted that the hypothesized activation of centrally acting, endogenous opioid peptides in the CNS in response to acupuncture stimulation cannot completely explain why acupuncture needling is conventionally applied to an acupoint adjacent to the area of pain (Goldman et al., 2010). In mouse models of inflammatory pain, Goldman et al. (2010) found that analgesic effects from manual acupuncture are mediated by the release of the transmitter adenosine. Injecting the mice after acupuncture treatment with deoxycoformycin, an adenosine deaminase inhibitor, prolonged the accumulation of adenosine and the antinociceptive effects of acupuncture. The researchers suggest that activation of the adenosine $A_{1}$ receptor is necessary for acupuncture analgesia (Goldman et al., 2010).

\section{Non-opioid Mechanisms}

Conversely, other research using human subjects failed to demonstrate naloxone reversal of EA analgesia, calling into question the premise that endorphins play a significant role in acupuncture analgesia (Chapman et al., 1983). In that study, 14 healthy adult volunteers who demonstrated EA analgesia during electrical stimulation of the LI4 acupoint were randomly assigned to naloxone $1.2 \mathrm{mg}$ or normal 
saline (Chapman et al., 1983). Naloxone failed to reverse pain thresholds elevated by acupuncture, suggesting that other mechanisms are involved in acupuncture-induced analgesia (Chapman et al., 1983).

\section{THE ROLE OF THE ENDOCANNABINOID SYSTEM (ECS) IN ELECTROACUPUNCTURE (EA) ANALGESIA}

Greater understanding of the ECS has encouraged investigations into the role of the ECS in acupuncture analgesia. This research is discussed below.

\section{EA-Induced Analgesia and Anti-inflammatory Effects Depend on $\mathrm{CB}_{1}$ Receptors and/or $\mathrm{CB}_{2}$ Receptors}

EA analgesia in inflammatory pain relates to the dopamine system and $\mathrm{CB}_{1}$ receptors in the striatum (Shou et al., 2013). In the complete Freund's adjuvant (CFA)-induced model of arthritis in mice, EA significantly increased $\mathrm{CB}_{1}$ receptor expression in the striatum and prolonged paw withdrawal latency; both effects were attenuated by the $\mathrm{CB}_{1}$ receptor antagonist AM251, indicating an important role for the $\mathrm{CB}_{1}$ receptor in EAinduced analgesia (Shou et al., 2013). The study researchers also reported that EA upregulated dopamine $\mathrm{D}_{1}$ and $\mathrm{D}_{2}$ receptor mRNA expression in the corpus striatum, which was effectively blocked by AM251 (Shou et al., 2013). They suggested that EA analgesia in inflammatory pain is due to cross-modulation between the dopamine system and $\mathrm{CB}_{1}$ in the striatum (Shou et al., 2013).

$\mathrm{CB}_{1}$ and $\mathrm{CB}_{2}$ receptors contribute to antinociceptive and anti-inflammatory effects of EA in arthritis of the rat temporomandibular joint. In one study, researchers found that EA significantly inhibited mechanical hypernociception in rats with acute arthritis induced by zymosan in the temporomandibular joint (TMJ) (Gondim et al., 2012). This effect was reversed by AM251, although AM251 failed to affect the EA-induced anti-inflammatory response in the TMJ (Gondim et al., 2012). In contrast, the $\mathrm{CB}_{2}$ receptor antagonist AM630 reversed the EA-induced anti-inflammatory effect but did not alter its antinociceptive effect (Gondim et al., 2012). These findings are supported by another study implicating the involvement of $\mathrm{CB}_{1}$ receptors in EA-induced orofacial antinociception among rats exposed to noxious facial heat (Almeida et al., 2016). In this experimental study, EA alone at acupoint ST36 induced antinociception that was blocked by pretreatment with AM251, but not by AM630 (Almeida et al., 2016). Moreover, the antinociceptive effects of EA were prolonged and intensified by pretreatment with an endocannabinoid metabolizing enzyme inhibitor (MAFP) or an anandamide reuptake inhibitor (VDM11) (Almeida et al., 2016). Acupuncture at ST36 (located below the knee) is generally used to treat dysfunctional gastrointestinal activity (Cheong et al., 2013) and rarely for diseases of the head and mouth (Yang Y. et al., 2012). However, the study by Almeida et al. (2016) revealed that ST36 is also related to the ECS.

\section{$\mathrm{CB}_{1}$ Receptors in the vIPAG Are Critically Important for the Mechanisms of the EA Antinociceptive Effect}

The vlPAG midbrain region is an important site of action in cannabinoid-induced antinociception and a likely supraspinal site of orexin antinociception (Ho et al., 2011). Orexin A and $\mathrm{B}$ are hypothalamic peptides that activate postsynaptic orexin 1 and orexin 2 receptors $\left(\mathrm{OX}_{1}\right.$ Rs and $\left.\mathrm{OX}_{2} \mathrm{Rs}\right)$, which have many roles in physiological processes including energy homeostasis, stress processing, visceral functions, reward seeking behavior, cognition, endocrine functions, arousal, and pain modulation (Razavi and Hosseinzadeh, 2017). $\mathrm{OX}_{1}$ Rs and $\mathrm{OX}_{2} \mathrm{Rs}$ are densely distributed in the PAG (Ho et al., 2011). In particular, orexin A can induce an opioid-independent analgesic mechanism that is mediated by $\mathrm{OX}_{1} \mathrm{R}$-initiated 2AG signaling in the vlPAG (Ho et al., 2011; Chen et al., 2018). Subsequent research using murine pain models has demonstrated how low-frequency median nerve stimulation (MNS) using acupuncture needles at the PC6 acupoint (EAPC6) induces analgesia involving both $\mathrm{CB}_{1}$ receptors and $\mathrm{OX}_{1}$ Rs (Chen et al., 2018). MNS-PC6-induced antinociception (a procedure equivalent to EA-PC6) was prevented by systemic blockade of $\mathrm{OX}_{1} \mathrm{Rs}$ or $\mathrm{CB}_{1}$ receptors, but not by opioid receptor antagonists (Chen et al., 2018). Systemic blockade of $\mathrm{OX}_{1} \mathrm{Rs}$ or $\mathrm{CB}_{1}$ receptors also prevented the EA-PC6-induced reduction in GABA levels in the vlPAG microdialysate (Chen et al., 2018). Notably, EA-PC6-induced analgesia was reduced by intravlPAG inhibition of 2-AG synthesis, implicating a cannabinoid (2-AG)-dependent mechanism, which was supported by the finding that EA-PC6-induced antinociception was markedly attenuated in $\mathrm{Cnrl}^{-/-}$mice, which lack the $\mathrm{CB}_{1}$ receptor (Chen et al., 2018). These findings suggest that PC6-targeting low-frequency MNS activates hypothalamic orexin neurons, releasing orexins that activate postsynaptic $\mathrm{OX}_{1} \mathrm{Rs}$ in the vlPAG to generate 2-AG, which inhibits $\mathrm{GABA}$ release through $\mathrm{CB}_{1}$ receptors in the vlPAG and induces analgesia by disinhibiting vlPAG outputs (Chen et al., 2018). These findings have been reinforced in further investigations by these researchers, who report that repeated EA-PC6 treatments remained fully effective in morphine-tolerant mice with neuropathic pain caused by chronic constriction injury (CCI) of the sciatic nerve, via a mechanism involving $\mathrm{OX}_{1} \mathrm{Rs}$ and $\mathrm{CB}_{1}$ receptors (Lee et al., 2020).

In other research involving mice with knee osteoarthritis, EA increased the levels of $\mathrm{CB}_{1}$ receptors and 2-AG in the vlPAG to reduce chronic knee osteoarthritis pain; the effect of EA on pain hypersensitivity was reversed when AM251 was injected into the vlPAG (Yuan et al., 2018b). Subsequent research by the same group discovered that knocking out the $\mathrm{CB}_{1}$ receptor on GABAergic neurons abolished most of the antinociceptive effects of EA in mice with CCI or knee osteoarthritis, while knocking out the $\mathrm{CB}_{1}$ receptor on glutamatergic neurons in the vlPAG only partly reduced the effects of EA (Zhu et al., 2019). The researchers 
proposed that inhibition of GABAergic neurons and activation of glutamatergic neurons in the vlPAG through $\mathrm{CB}_{1}$ receptors contribute to EA-induced analgesia (Zhu et al., 2019).

Counterintuitively, while some research has shown that low doses of $\mu$-opioid receptor antagonists levonaloxone, naltrexone, cyclazocine, and diprenorphine block EA analgesia (Cheng and Pomeranz, 1980), other investigations have demonstrated that ultra-low-dose naltrexone (0.001-0.004 mg/day) enhances opiate-induced analgesia while also reducing opioid tolerance and dependence in chronic pain conditions (Chindalore et al., 2005; Webster, 2007). Some researchers have hypothesized that low-dose naltrexone (3-4.5 mg/day) could synergistically enhance acupuncture-induced pain relief (Hesselink and Kopsky, 2011). In support of this hypothesis, low-dose naltrexone appears to exert hypoalgesic effects in healthy human volunteers exposed to noxious electrocutaneous stimulation (France et al., 2007), blocks acute tolerance to morphine and attenuates morphine-elicited thermal hyperalgesia in rats (McNaull et al., 2007), and enhances cannabinoid-induced antinociception in rats (Paquette and Olmstead, 2005). Preclinical research has effectively illustrated interactions between the cannabinoid system and opioid antinociception, showing that AM251 can completely block morphine-induced peripheral and central antinociception in a rat model of inflammatory pain and in the tail-flick test in mice, while AM630 is only partially effective or fails to antagonize antinociception induced by morphine (Pacheco et al., 2008, 2009). These researchers have therefore suggested that $\mu$-opioid-induced antinociception involves peripheral (Pacheco et al., 2008) or central (Pacheco et al., 2009) activation of $\mathrm{CB}_{1}$ and/or $\mathrm{CB}_{2}$ receptors that potentiate the opioid-induced antinociceptive mechanisms. Other evidence suggests that a regimen of low-dose THC combined with low-dose morphine enhances opioid analgesic potency without increasing undesirable side effects (Cichewicz, 2004). Further support for considerable crosstalk between the opioid and endocannabinoid pathways comes from studies involving transgenic mice with inactivated $\mathrm{CB}_{1}$ or $\mathrm{CB}_{2}$ receptors [cnr1 and $c n r 2$ knockout (KO) mice], which exhibit marked reductions in peripheral or spinal morphine analgesia (Desroches et al., 2014). This loss in morphine analgesia was not explained by downregulation in $\mu$-opioid spinal expression nor by altered binding properties or $G$ protein coupling of the $\mu$-opioid receptor in $c n r 1 \mathrm{KO}$ and $c n r 2 \mathrm{KO}$ mice (Desroches et al., 2014).

\section{$\mathrm{CB}_{2}$ Receptors in the Peripheral Tissue Mediate the Anti-inflammatory Effects of Acupuncture}

It is possible that the roles of $\mathrm{CB}_{1}$ and $\mathrm{CB}_{2}$ receptors differ according to the type of pain condition. For instance, EA significantly increased levels of AEA in inflamed skin tissue and produced antinociceptive effects by activating peripheral $\mathrm{CB}_{2}$ receptors in a rat model of CFA-induced inflammatory pain (Chen et al., 2009), while $\mathrm{CB}_{1}$ receptors appeared to mediate the anti-inflammatory effect of EA in a rat model of migraine (Zhang et al., 2016). In the CFA model of inflammatory pain induced by the local injection of CFA into the hind paw of rats, local pretreatment with AM630 significantly attenuated the antinociceptive effect of EA, whereas local pretreatment with AM251 had no significant effect on EA analgesia (Chen et al., 2009). In a follow-up study using the same inflammatory pain model, the researchers found increased numbers of $\mathrm{CB}_{2}$ receptors on macrophages, T-lymphocytes, and keratinocytes in the epidermis and dermis in response to CFA injections; further increases were observed in all of these cells expressing $\mathrm{CB}_{2}$ receptors in the inflamed skin of rats in the CFA plus 2 and $100 \mathrm{~Hz}$ EA groups (Zhang et al., 2010). CFA plus $2 \mathrm{~Hz}$ EA and CFA plus $100 \mathrm{~Hz}$ EA also significantly increased mRNA and protein levels of $\mathrm{CB}_{2}$ receptors in the inflamed skin tissue (Zhang et al., 2010). In another study involving rats with CFA-induced inflammatory pain, EA appeared to reduce pain by inhibiting activation of the NLRP3 inflammasome in inflamed skin tissue through $\mathrm{CB}_{2}$ receptor stimulation (Gao et al., 2018). Similarly, other researchers found that EA-induced activation of the $\mathrm{CB}_{2}$ receptor inhibited chronic pain in mice with knee osteoarthritis (Yuan et al., 2018a). In their study, EA treatment was associated with significant increases in levels of $\mathrm{CB}_{2}$ receptor expression in fibroblasts and significant reductions in IL-1 $\beta$-positive cells in the knee meniscus; knockout of the $\mathrm{CB}_{2}$ receptor blocked EA analgesia and EA had no effect upon IL-1 $\beta$ expression in $C B 2^{-/-}$mice (Yuan et al., 2018a).

EA analgesia in inflammatory pain may also be due to an interaction between peripheral $\mathrm{CB}_{2}$ receptors and endogenous opioids ( $\mathrm{Su}$ et al., 2011). $\beta$-Endorphin, the endogenous ligand of the opioid peptide, is derived from the precursor proopiomelanocortin (POMC). In a rat model of inflammatory pain, mRNA levels of POMC and protein levels of $\beta$-endorphin were significantly increased in inflamed skin tissues after rats were treated with the $\mathrm{CB}_{2}$ receptor agonist AM1241 or EA, while AM630 significantly reduced these effects (Su et al., 2011). Percentages of $\beta$-endorphinimmunoreactive keratinocytes, macrophages, and T-lymphocytes were also significantly increased by AM1241 or EA, whereas pretreatment with AM630 blocked these effects (Su et al., 2011). Thus, a peripheral interaction between $\mu$-opioid receptors and $\mathrm{CB}_{2}$ receptors is implicated in EA analgesia in inflammatory pain.

The same group of researchers subsequently reported that EA appears to reduce inflammatory pain and proinflammatory cytokine expression by activating $\mathrm{CB}_{2}$ receptors in CFA-induced skin inflammation (Su et al., 2012). EA at GB30 and GB34 acupoints and also local injections of AM1241 significantly decreased thermal hyperalgesia and mechanical allodynia in inflammatory skin tissue; the antinociceptive effect of EA was blocked by pretreatment with AM630 (Su et al., 2012). EA or AM1241 treatment also significantly reduced IL-1 $\beta$, IL-6, and TNF- $\alpha$ mRNA and protein levels in inflamed skin tissue; these inhibitory effects were reversed by AM630 pretreatment (Su et al., 2012).

The placebo effect in acupuncture analgesia is well-recognized (Musial, 2019). The ECS can also play an important role in placebo analgesia. Research has revealed the secretion of 
TABLE 1 | Reports published between 2009 and 2020 (cited in ascending date order) describing the involvement of the ECS in EA analgesia.

\begin{tabular}{|c|c|c|c|c|}
\hline Pain model & $\begin{array}{l}\text { Acupuncture } \\
\text { treatment }\end{array}$ & Major findings & Conclusions & References \\
\hline $\begin{array}{l}\text { Inflammatory pain/CFA } \\
\text { injection }\end{array}$ & $\begin{array}{l}2 \text { or } 100 \mathrm{~Hz} \text { EA (1 mA, } \\
30 \text { min) at GB30 and } \\
\text { GB34, on days 2, 4, } \\
\text { and } 6 \text { after CFA } \\
\text { injection }\end{array}$ & $\begin{array}{l}\text { - EA at } 2 \text { and } 100 \mathrm{~Hz} \text { significantly reduced thermal } \\
\text { hyperalgesia and mechanical allodynia associated with CFA } \\
\text { injections. } \\
\text { - EA significantly increased endogenous levels of AEA in } \\
\text { inflamed skin tissue. } \\
\text { - EA-induced antinociception was significantly reduced by } \\
\text { AM630, but not significantly altered by AM251. AM251 and }\end{array}$ & $\begin{array}{l}\text { EA appears to enhance the } \\
\text { local release of endogenous } \\
\text { AEA from inflamed skin tissue. } \\
\text { EA analgesia in inflammatory } \\
\text { pain involves the activation of } \\
\text { peripheral } \mathrm{CB}_{2} \text { receptors. }\end{array}$ & $\begin{array}{l}\text { Chen et al., } \\
2009\end{array}$ \\
\hline
\end{tabular}

Inflammatory pain/CFA injection

Inflammatory pain/CFA injection

Inflammatory pain/CFA injection

Inflammatory pain/zymosan administration in the TMJ

Inflammatory pain/CFA injection
2 or $100 \mathrm{~Hz}$ (1 mA, $30 \mathrm{~min}$ ) at GB30 and GB34 once every other day, starting from the second day after CFA injection, for 7 days $2 \mathrm{~Hz}$ EA (1 mA, $30 \mathrm{~min}$ ) at GB30 and GB34, on days 2,4 , and 6 after CFA injection AM630, but not significantly altered by AM251. AM251 and were each given as subcutaneous injections into the dorsal surface of the left hind paw 5 min prior to sham EA or EA treatment.

- EA at 2 and $100 \mathrm{~Hz}$ significantly increased $\mathrm{CB}_{2} \mathrm{R}$ mRNA and protein expression in inflamed skin tissue.

- EA 2 and $100 \mathrm{~Hz}$ significantly increased quantities of $\mathrm{CB}_{2} \mathrm{R}$-immunoreactive keratinocytes, macrophages, and T-lymphocytes in inflamed skin tissue.

- EA or AM1241 significantly reduced thermal hyperalgesia and mechanical allodynia; pretreatment with $\beta$-funaltrexamine (a selective $\mu$-opioid receptor antagonist) attenuated these effects.

- EA or AM1241 significantly increased POMC mRNA and $\beta$-endorphin protein levels in inflamed skin tissues; these effects were significantly reduced by pretreatment with AM630. AM1241 or AM630 was injected subcutaneously into the dorsal surface of the left hind paw 5 min before each session of sham EA or EA treatment.

- EA also significantly increased the percentage of $\beta$-endorphin-immunoreactive keratinocytes, macrophages, and T-lymphocytes in inflamed skin tissue; AM630 prevented these effects.

$2 \mathrm{~Hz}$ EA (1 mA, $30 \mathrm{~min})$ at GB30 and GB34, on days 2, 4, and 6 after CFA injection

$10 \mathrm{~Hz}$ EA (3 mA $30 \mathrm{~min})$ at LI4, LI11, ST36 and ST34, $1 \mathrm{~h}$ before or $2 \mathrm{~h}$ after zymosan administration in the TMJ

2/100 Hz EA (1.0, 2.0, $3.0 \mathrm{~mA}, 20 \mathrm{~min})$ at ST36 and BL60, once every other day starting from the 4th day after CFA injection, for 4 sessions
- EA or AM1241 treatment significantly reduced thermal hyperalgesia and mechanical allodynia after CFA injection. - AM630 significantly attenuated EA antinociception. AM1241 or AM630 was injected subcutaneously into the dorsal surface of the left hind paw 5 min before each session of sham EA or EA treatment.

- EA or AM1241 treatment significantly reduced IL-1 $\beta$, IL-6, and TNF- $\alpha$ mRNA and protein levels in inflamed skin tissue.

- The inhibitory effects of EA on these cytokines were significantly reversed by pretreatment with AM630.

- EA significantly inhibited zymosan-induced hypernociception.

- EA antinociception was significantly reversed by AM251.

- EA anti-inflammatory effects were reversed by AM630. Both AM251 and AM630 were given as single, IP injections 10 min prior to EA treatment.

- $C B_{1} R$ and $C B_{2} R$ gene expression was upregulated $6 \mathrm{~h}$ after zymosan-induced arthritis in EA-treated rats.

- In EA-treated rats, $C B_{1} R$ gene expression was significantly increased at $6 \mathrm{~h}$ after zymosan administration and increased still further at $24 \mathrm{~h}$, whereas $C B_{2} R$ gene expression peaked at $6 \mathrm{~h}$ after zymosan administration and was downregulated at $24 \mathrm{~h}$.

- EA improved thermal hyperalgesia and significantly increased levels of $\mathrm{CB}_{1}$ expression in rat striatum.

- AM251 significantly attenuated EA-induced increases in $\mathrm{CB}_{1}$ expression. Single, IP injections of AM251 were administered on study day 10.

- EA upregulated dopamine $D_{1}$ and $D_{2}$ receptor mRNA expression in the corpus striatum, which was effectively blocked by AM251.
EA upregulates $\mathrm{CB}_{2}$ receptor expression in keratinocytes and inflammatory cells in inflamed skin tissue.

EA increases endogenous opioid expression in keratinocytes and infiltrating immune cells at the inflammatory site by activating peripheral $\mathrm{CB}_{2}$ receptors.

EA activation of $\mathrm{CB}_{2}$ receptors reduces inflammatory pain and proinflammatory cytokine expression in inflamed tissue.

Antinociceptive and anti-inflammatory effects of EA appeared to be mediated through $\mathrm{CB}_{1}$ and $\mathrm{CB}_{2}$ receptor activation.

EA analgesia in inflammatory pain is associated with

Shou et al., upregulation of dopamine and $\mathrm{CB}_{1}$ receptors in the rat corpus striatum.
Zhang et al., 2010

Su et al., 2011

Su et al., 2012

Gondim et al., 2012 
TABLE 1 | Continued

\begin{tabular}{|c|c|c|c|c|}
\hline Pain model & Acupuncture treatment & Major findings & Conclusions & References \\
\hline $\begin{array}{l}\text { Migraine (induced } \\
\text { by electrical }\end{array}$ & $\begin{array}{l}\text { Ipsilateral 2/15 Hz EA ( } 1 \mathrm{~mA} \text {, } \\
30 \mathrm{~min} \text { ) at GB20 and TE5 once }\end{array}$ & $\begin{array}{l}\text { - EA significantly attenuated TGES-induced } \\
\text { increases in serum CGRP and PGE } 2 \text { levels, and }\end{array}$ & $\begin{array}{l}\mathrm{CB}_{1} \text { receptors appeared to } \\
\text { mediate EA }\end{array}$ & $\begin{array}{l}\text { Zhang et al. } \\
2016\end{array}$ \\
\hline
\end{tabular}

stimulation of the daily for 5 days before TGES

trigeminal ganglion;

TGES)

\section{Orofacial pain}

(induced by

noxious heat

applied to the face)

Inflammatory

pain/MIA injection

Inflammatory

pain/MIA injection

Heat hyperalgesia and neuropathic pain

Inflammatory pain/CFA injection

Inflammatory and neuropathic pain
$100 \mathrm{~Hz}$ EA (0.5 mA, $20 \mathrm{~min})$ at ST36

Knee OA model:

2, 15, or $100 \mathrm{~Hz}$ EA (1 mA, $30 \mathrm{~min})$ at Ex-LE4 and ST35, starting from 2 days after IA-injected MIA, once every other day for 4 weeks
Knee OA model:

$2 \mathrm{~Hz}$ EA (1 mA, $30 \mathrm{~min}$ ) at Ex-LE4 and ST35, starting from 2 days after IA-injected MIA, once every other day for 4 weeks

Hot-plate test:

$2 \mathrm{~Hz}$ EA-PC6 (2 mA, for $20 \mathrm{~min}$ ) CCl model:

EA-PC6, non-MNS, or sham-PC6 were applied on postoperative day 8

QD $2 \mathrm{~Hz}$ EA (1 mA, $30 \mathrm{~min}$ ) at GB30 and GB34 on days 2, 4, and 6 after CFA injections
CCl model:

QD $2 \mathrm{~Hz}$ EA (1 mA, $30 \mathrm{~min})$ at GB30 and GB34, starting from the 8th postoperative day and ending on the 14th postoperative day inhibited the TGES-induced increase in neurogenic PPE.

- EA significantly attenuated TGES-induced increases in COX2 and IL-1 $\beta$ protein levels in the trigeminal ganglion.

- The effects of EA were reversed by $\mathrm{CB}_{1} \mathrm{R}$ antagonism.

- EA-induced antinociception was prolonged and intensified by pretreatment with an endocannabinoid metabolizing enzyme inhibitor (MAFP) and an anandamide reuptake inhibitor (VDM11).

- EA-induced antinociception was blocked by pretreatment with AM251, but not by AM630. All study drugs were injected as single, IP doses, 10 min prior to EA treatment.

- Chronic pain-induced reductions in levels of $\mathrm{CB}_{1} \mathrm{Rs}$ and 2-AG expression in the midbrain were reversed by EA treatment.

- Microinjection of AM251 into the VIPAG reversed the effects of EA on pain hypersensitivity and DNIC function. - In GABA-CB1-/ - mice subjected to knee OA induction, the reduced thermal latencies and tactile thresholds were not significantly affected by EA. Similarly, EA had no effect on the reduction in $5-\mathrm{HT}$ levels in the medulla following the induction of knee OA in GABA-CB1-/mice.

- EA significantly increased levels of $\mathrm{CB}_{2} \mathrm{R}$ expression in fibroblasts and significantly reduced IL-1 $\beta$-positive cells in the knee meniscus.

- Knockout of the $\mathrm{CB}_{2} \mathrm{R}$ blocked EA analgesia.

- EA-PC6 reduced acute thermal nociceptive responses and neuropathy-induced mechanical allodynia; these effects were prevented by systemic or intra-vIPAG injection of an antagonist of $\mathrm{OX}_{1} \mathrm{Rs}$ or $\mathrm{CB}_{1} \mathrm{Rs}$, but not by opioid receptor antagonists.

- EA-PC6 increased the number of c-Fos-immunoreactive hypothalamic orexin neurons, and led to higher orexin A and lower GABA levels in the vIPAG.

- EA-PC6-induced nociception was prevented by intra-vIPAG inhibition of 2-AG synthesis and was attenuated in $\mathrm{Cnr1}^{-/-}$mice.

- EA significantly reduced CFA-induced thermal hyperalgesia and mechanical allodynia and attenuated CFA-induced activation of the NLRP3 inflammasome in inflamed skin tissues.

- In vitro studies in a rat alveolar macrophage cell line revealed that activation of $\mathrm{CB}_{2}$ receptors inhibited NLRP3 inflammasome activation. anti-inflammatory effects in

a rat model of migraine.

EA orofacial antinociception appeared to involve activation of $\mathrm{CB}_{1}$ receptors.

Almeida et al., 2016

It appears that the 2-AG-CB 1 R-GABA-5-HT signaling pathway underlies the effects of EA on descending inhibitory control of 5-HT, improving DNIC function and inhibiting chronic pain. $\mathrm{CB}_{1}$ Rs on GABAergic neurons were involved in the effects of EA on DNIC function and descending inhibitory control of 5-HT in the medulla.

EA reduced levels of IL-1 $\beta$ expression by activating $\mathrm{CB}_{2}$ receptors, which effectively reduced chronic pain in mice with knee OA.

EA-PC6 induces the release of an endogenous neuropeptide (orexin) from the hypothalamus to inhibit pain responses in mice through a $\mathrm{CB}_{1} \mathrm{R}$-dependent cascade that reduces inhibitory GABAergic control in the vIPAG.

EA appears to relieve inflammatory pain by inhibiting NLRP3 inflammasome activation in inflamed skin tissues through $\mathrm{CB}_{2}$ receptors.
Yuan et al., $2018 b$

Yuan et al., $2018 \mathrm{a}$

Chen et al., 2018

Gao et al., 2018 
TABLE 1 | Continued

\begin{tabular}{|c|c|c|c|c|}
\hline Pain model & Acupuncture treatment & Major findings & Conclusions & References \\
\hline
\end{tabular}

2-AG, 2-arachidonoylglycerol; 5-HT, 5-hydroxytryptamine or serotonin; $A M 1421, C B_{2}$ receptor agonist; $A M 251, C B_{1}$ receptor antagonist; $A M 630, C B_{2}$ receptor antagonist; BID, twice daily; BL60, Kunlun; $C B_{1} R$, cannabinoid 1 receptor; CCl, chronic constriction nerve injury; CFA, complete Freund's adjuvant; CGRP, calcitonin gene-related peptide; DNIC, diffuse noxious inhibitory control; EA, electroacupuncture; ECS, endocannabinoid system; Ex-LE4, Neixiyan; GB30, Huantiao; GABA, $\gamma$ aminobutyric acid; GB20, Fengchi; GB34, Yanglingquan; IA, intra-articular; IP, intraperitoneal; IT, intrathecal; LI4, Hegu; LI11, Quchi; MIA, monosodium iodoacetate; MNS, median nerve stimulation; non-MNS, the same electrical stimulation as in the MNS group via acupuncture needles inserted in the middle of the lateral deltoid muscle (a non-median nerve-innervated location); OA, osteoarthritis; $O X_{1} R$, orexin 1 receptor; PC6, Neiguan; PPE, plasma protein extravasation; QD, once daily; p-ERK1/2, phosphorylated-extracellular signal-regulated kinase 1/2; $P G E_{2}$, prostaglandin $E_{2}$; sham-PC6, bilateral needle insertion at the PC6 acupoint without electrical stimulation; ST34, Liangqiu; ST35, Dubi; ST36, Zusanli; TE5, Waiguan; TGES, electrical stimulation of the trigeminal ganglion; vIPAG, ventrolateral periaqueductal gray.

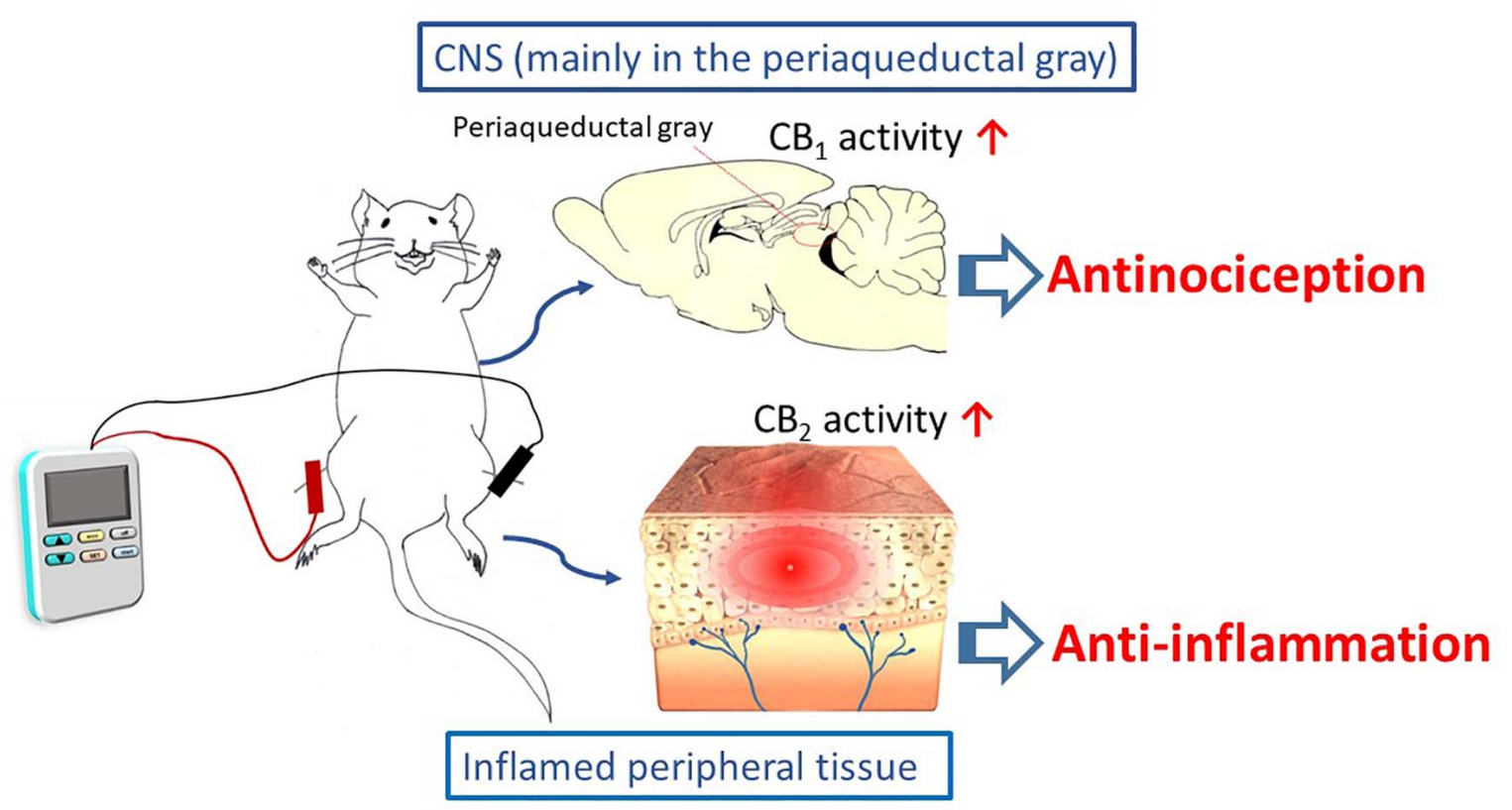

SCHEME 1 | The cannabinoid pathway, including the $\mathrm{CB}_{1}$ and $\mathrm{CB}_{2}$ receptors, mediates the analgesic and anti-inflammatory effects of electroacupuncture.

endogenous endocannabinoids from the brain during a placebo response to pain, when non-opioid drugs were used in the preconditioning phase (Benedetti, 2012). For instance, the specific $C_{1}$ receptor antagonist rimonabant can effectively block placebo analgesia elicited by non-opioid pharmacological conditioning with non-steroidal anti-inflammatory drugs (NSAIDs) in healthy volunteers (Benedetti et al., 2011). More animal and human studies are needed to determine how $\mathrm{CB}_{1}$ receptors contribute to placebo and acupuncture analgesia.

Publications from 2009 onward supporting the involvement of endocannabinoids in EA analgesia are summarized in Table 1.

\section{Functions of the Acupoints Selected in the Reviewed Studies}

The acupoints reviewed in this article and listed in Table 1 are primarily found in the upper and lower limbs. GB30 (Huantiao) is located on the sciatic nerve path and is used in TCM as a basic point in low back pain (Shao et al., 2015) and for motor function treatment (Yeo et al., 2014). GB34 (Yanglingquan) is found on the common peroneal nerve and is used as an additional point to GB30 when low back pain is associated with lower extremity numbness and pain (Shao et al., 2015). Stimulation 
of GB34 activates the prefrontal cortex, the precentral gyrus and putamen in patients with Parkinson's disease; areas of the brain that exhibit dysfunction due to nigral dopamine depletion (Yeo et al., 2014). LI4 (Hegu) is located on the dorsum of the hand and LI11 (Quchi) at the elbow; both are suggested to be particularly useful for improving neck-shoulder-arm disorders (Shiro et al., 2014), with clinical evidence describing the relief of stress, facial pain, headache, toothache, neck, and shoulder pain (LI4) (He et al., 2004; Shen et al., 2009; Pavão et al., 2010; Grillo et al., 2014; Wang et al., 2015), pain-related conditions, and common fever (LI11) (Choi et al., 2018). Acupoints ST34 (Liangqiu, above the laterosuperior border of the patella), ST35 (Dubi, at the lower border of the patellar) and ST36 (Zusanli, on the anterior of the leg lateral to the edge of the tibia, below ST35) are effective for postoperative pain control (Liu et al., 2015); stimulation of ST36 is frequently used to treat dyskinesia and facilitate motor recovery after stroke, to treat pain, hypertension, and other physiological dysfunctions (Sun et al., 2019) such as migraine (Zhao et al., 2012). The acupoint combination of GB20 (Fengchi, situated below the base of the skull) and TE5 (Waiguan, near the dorsal wrist crease between the radius and ulna) is frequently used for treating migraine (Zhao et al., 2012), while EX-LE4 (Neixiyan) and ST35 (both located on the knee) are frequently paired for pain relief, such as in knee osteoarthritis (Ng et al., 2003). PC6 (Neiguan, on the palm side of the wrist and located on the median nerve path) is a classical acupoint that is used to treat cardiovascular disorders (Li et al., 2012), for providing postoperative analgesia (Xie et al., 2014), and for preventing nausea and vomiting (Cheong et al., 2013), while BL60 (Kunlun, on the posterior aspect of the knee) is frequently used in acupoint combinations for the treatment of low back pain (Lee et al., 2013).

\section{CONCLUSION}

No single mechanism can explain EA analgesia. Early preclinical investigations demonstrated that naloxone antagonizes EA analgesia, suggesting that the analgesic action is related to the release of a morphine-like factor in the CNS, supporting the endorphin hypothesis of acupuncture analgesia (Pomeranz and Chiu, 1976). Subsequent research revealed elevated levels of $\beta$-endorphin in human cerebrospinal fluid after acupuncture for recurrent pain (Clement-Jones et al., 1980) and in plasma met-enkephalin after EA in patients with chronic pain (Kiser et al., 1983). Different frequencies of EA have been found to elucidate different opiate secretions; lowfrequency EA $(2 \mathrm{~Hz})$ is associated with analgesia involving met-enkephalin, $\beta$-endorphin, and endomorphin, which activate the $\mu$ - and $\delta$-opioid receptors, while high-frequency EA $(100 \mathrm{~Hz})$ stimulates dynorphin, which activates the $\kappa$-opioid receptor (Han, 2004). Evidence on EA analgesia also implicates the midbrain monoamines serotonin and norepinephrine, and anti-inflammatory mechanisms mediated by opioid and non-opioid receptors in the periphery (Zhang et al., 2014).
The discovery of the cannabinoid receptors and endocannabinoids has inspired many investigations that have targeted ECS proteins, the cannabinoid receptors, and the enzymes responsible for the biosynthesis and degradation of the endogenous cannabinoid receptor ligands, in the hope of discovering therapeutic targets that can be treated with novel drugs for a wide range of diseases, including pain (Stasiulewicz et al., 2020). However, these investigations have been complicated by adverse effects arising from the multidirectional nature of the ECS and its inter-relationships with other pharmacological systems and biochemical pathways (Stasiulewicz et al., 2020).

EA interventions are potentially appropriate for activating the ECS. The evidence discussed in this review suggests that EA inhibits inflammatory and neuropathic pain, and that these effects may be associated with modulations of cannabinoid signaling within the ECS. This signaling is illustrated in Scheme 1. It appears that the cannabinoid pathway mediates the analgesic and anti-inflammatory effects of acupuncture, via the $\mathrm{CB}_{1}$ and $\mathrm{CB}_{2}$ receptors, respectively. However, the current results are all generated from animal studies. Evidence from animal studies remains fragmentary and clinical evidence is lacking. In contrast, evidence for the endorphins theory is supported by not only animal studies, but also human investigations.

Clearly, EA increases different types of endogenous opioids in humans, while naloxone, an opioid receptor antagonist, appears to attenuate acupuncture analgesia in humans. To fully inform the ECS theory of EA analgesia, further human studies are called for. As with the evidence in support of the endorphin hypothesis, biochemical evidence such as measurements of cerebrospinal fluid (CSF) concentrations of endocannabinoids are needed to show how the ECS is influenced by acupuncture interventions. For instance, one study has identified significantly lower CSF concentrations of AEA in patients with chronic migraine and those with probable chronic migraine and probable analgesic-overuse headache compared with non-migraine controls (Sarchielli et al., 2007). Interestingly, $\mathrm{CB}_{1}$ receptor antagonism is a promising strategy in the treatment of obesity. However, CNS side effects associated with rimonabant and other $\mathrm{CB}_{1}$ receptor antagonists emphasized the need for new classes of peripherally acting $\mathrm{CB}_{1}$ receptor antagonists that do not affect the intricate balance between central and peripheral physiological signaling (Sharma et al., 2015; Lv et al., 2019). Ongoing efforts to develop safer selective peripherally acting $\mathrm{CB}_{1}$ receptor antagonists, potent novel $\mathrm{CB}_{1}$ receptor antagonists or inverse agonists may eventually result in therapeutics that target $\mathrm{CB}_{1}$ receptors with reduced CNS side effects (Sharma et al., 2015; Yadav and Murumkar, 2018; Khan N. et al., 2019; Micale et al., 2019). At that point, it would be interesting to determine whether or not $\mathrm{CB}_{1}$ receptor antagonists attenuate $\mathrm{EA}$ analgesia in humans. We would then expect to have much more clarity around the biological basis underlying the mechanisms of EA-induced antinociception involving $\mathrm{CB}_{1}$ and $\mathrm{CB}_{2}$ receptors in the ECS. 


\section{AUTHOR CONTRIBUTIONS}

Y-HC conceived and advised on the manuscript. IM wrote the first draft of the manuscript. Both authors revised the manuscript and agreed with the published version of the manuscript.

\section{FUNDING}

This work was supported by grants from the China Medical University, Taichung, Taiwan (CMU108-MF-58)

\section{REFERENCES}

Acharya, N., Penukonda, S., Shcheglova, T., Hagymasi, A. T., Basu, S., and Srivastava, P. K. (2017). Endocannabinoid system acts as a regulator of immune homeostasis in the gut. Proc. Natl. Acad. Sci. U.S.A. 114, 5005-5010. doi: $10.1073 /$ pnas. 1612177114

Aizpurua-Olaizola, O., Elezgarai, I., Rico-Barrio, I., Zarandona, I., Etxebarria, N., and Usobiaga, A. (2017). Targeting the endocannabinoid system: future therapeutic strategies. Drug Discov. Today 22, 105-110. doi: 10.1016/j.drudis. 2016.08.005

Almeida, R. T., Romero, T. R., Romero, M. G., de Souza, G. G., Perez, A. C., and Duarte, I. D. (2016). Endocannabinoid mechanism for orofacial antinociception induced by electroacupuncture in acupoint St36 in rats. Pharmacol. Rep. 68, 1095-1101. doi: 10.1016/j.pharep.2016.07.004

Baeumler, P. I., Conzen, P., and Irnich, D. (2019). High temporal summation of pain predicts immediate analgesic effect of acupuncture in chronic pain patients-a prospective cohort study. Front. Neurosci. 13:498.

Baeumler, P. I., Fleckenstein, J., Takayama, S., Simang, M., Seki, T., and Irnich, D. (2014). Effects of acupuncture on sensory perception: a systematic review and meta-analysis. PLoS One 9:e113731. doi: 10.1371/journal.pone.0113731

Barlas, P., Ting, S. L., Chesterton, L. S., Jones, P. W., and Sim, J. (2006). Effects of intensity of electroacupuncture upon experimental pain in healthy human volunteers: a randomized, double-blind, placebo-controlled study. Pain 122, 81-89. doi: 10.1016/j.pain.2006.01.012

Benedetti, F. (2012). Placebo-induced improvements: how therapeutic rituals affect the patient's brain. J. Acupunct. Meridian Stud. 5, 97-103. doi: 10.1016/j.jams. 2012.03.001

Benedetti, F., Amanzio, M., Rosato, R., and Blanchard, C. (2011). Nonopioid placebo analgesia is mediated by CB1 cannabinoid receptors. Nat. Med. 17, 1228-1230. doi: $10.1038 / \mathrm{nm} .2435$

Campolongo, P., and Fattore, L. (2015). Cannabinoid Modulation of Emotion, Memory, and Motivation. New York: Springer.

Chapman, C. R., Benedetti, C., Colpitts, Y. H., and Gerlach, R. (1983). Naloxone fails to reverse pain thresholds elevated by acupuncture: acupuncture analgesia reconsidered. Pain 16, 13-31. doi: 10.1016/0304-3959(83)90082-9

Chen, J. S., Kandle, P. F., Murray, I., Lauren, A., Fitzgerald, and Sehdev, J. S. (2020). Physiology, Pain. Treasure Island: StatPearls.

Chen, L., Zhang, J., Li, F., Qiu, Y., Wang, L., Li, Y. H., et al. (2009). Endogenous anandamide and cannabinoid receptor-2 contribute to electroacupuncture analgesia in rats. J. Pain 10, 732-739. doi: 10.1016/j.jpain.2008.12.012

Chen, N., Wang, J., Mucelli, A., Zhang, X., and Wang, C. (2017). Electroacupuncture is beneficial for knee osteoarthritis: the evidence from metaanalysis of randomized controlled trials. Am. J. Chin. Med. 45, 965-985. doi: 10.1142/s0192415x17500513

Chen, Y. H., Lee, H. J., Lee, M. T., Wu, Y. T., Lee, Y. H., Hwang, L. L., et al. (2018). Median nerve stimulation induces analgesia via orexin-initiated endocannabinoid disinhibition in the periaqueductal gray. Proc. Natl. Acad. Sci. U.S.A. 115, E10720-E10729.

Cheng, R. S., and Pomeranz, B. H. (1980). Electroacupuncture analgesia is mediated by stereospecific opiate receptors and is reversed by antagonists of type i receptors. Life Sci. 26, 631-638. doi: 10.1016/0024-3205(80)90239-8

Cheong, K. B., Zhang, J. P., Huang, Y., and Zhang, Z. J. (2013). The effectiveness of acupuncture in prevention and treatment of postoperative nausea and and by the "Chinese Medicine Research Center, China Medical University" from the Featured Areas Research Center Program within the framework of the Higher Education Sprout Project under the Ministry of Education (MOE) in Taiwan.

\section{ACKNOWLEDGMENTS}

We thank Sih-Ting Luo and Hsing-Hui Su for their assistance in producing the manuscript.

vomiting-a systematic review and meta-analysis. PLoS One 8:e82474. doi: 10.1371/journal.pone.0082474

Chindalore, V. L., Craven, R. A., Yu, K. P., Butera, P. G., Burns, L. H., and Friedmann, N. (2005). Adding ultralow-dose naltrexone to oxycodone enhances and prolongs analgesia: a randomized, controlled trial of oxytrex. J. Pain 6, 392-399. doi: 10.1016/j.jpain.2005.01.356

Chiurchiu, V., Battistini, L., and Maccarrone, M. (2015). Endocannabinoid signalling in innate and adaptive immunity. Immunology 144, 352-364. doi: 10.1111/imm.12441

Choi, V., Cobbin, D., and Walsh, S. (2018). Does modern research concerning chinese medicine acupoints relate to original prescriptions? if not, why not? Med. Acupunct. 30, 336-347.

Chou, R., Deyo, R., Friedly, J., Skelly, A., Hashimoto, R., Weimer, M., et al. (2017). Nonpharmacologic therapies for low back pain: a systematic review for an american college of physicians clinical practice guideline. Ann. Intern. Med. 166, 493-505. doi: 10.7326/m16-2459

Cichewicz, D. L. (2004). Synergistic interactions between cannabinoid and opioid analgesics. Life Sci. 74, 1317-1324. doi: 10.1016/j.lfs.2003.09.038

Clement-Jones, V., McLoughlin, L., Tomlin, S., Besser, G. M., Rees, L. H., and Wen, H. L. (1980). Increased beta-endorphin but not met-enkephalin levels in human cerebrospinal fluid after acupuncture for recurrent pain. Lancet 2, 946-949. doi: 10.1016/s0140-6736(80)92106-6

Deare, J. C., Zheng, Z., Xue, C. C., Liu, J. P., Shang, J., Scott, S. W., et al. (2013). Acupuncture for treating fibromyalgia. Cochrane Database Syst. Rev. 5:CD007070

Desroches, J., Bouchard, J. F., Gendron, L., and Beaulieu, P. (2014). Involvement of cannabinoid receptors in peripheral and spinal morphine analgesia. Neuroscience 261, 23-42. doi: 10.1016/j.neuroscience.2013.12.030

Di Marzo, V., and Petrocellis, L. D. (2006). Plant, synthetic, and endogenous cannabinoids in medicine. Annu. Rev. Med. 57, 553-574. doi: 10.1146/annurev. med.57.011205.135648

Endres, H. G., Böwing, G., Diener, H. C., Lange, S., Maier, C., Molsberger, A., et al. (2007). Acupuncture for tension-type headache: a multicentre, shamcontrolled, patient-and observer-blinded, randomised trial. J. Headache Pain 8, 306-314. doi: 10.1007/s10194-007-0416-5

France, C. R., Al'Absi, M., Ring, C., France, J. L., Harju, A., and Wittmers, L. E. (2007). Nociceptive flexion reflex and pain rating responses during endogenous opiate blockade with naltrexone in healthy young adults. Biol. Psychol. 75, 95-100. doi: 10.1016/j.biopsycho.2006.12.005

Fulmer, M. L., and Thewke, D. P. (2018). The endocannabinoid system and heart disease: the role of cannabinoid receptor type 2. Cardiovasc. Hematol. Disord. Drug Targets 18, 34-51. doi: 10.2174/1871529x18666180206 161457

Gao, F., Xiang, H. C., Li, H. P., Jia, M., Pan, X. L., Pan, H. L., et al. (2018). Electroacupuncture inhibits NLRP3 inflammasome activation through CB2 receptors in inflammatory pain. Brain Behav. Immun. 67, 91-100. doi: 10.1016/ j.bbi.2017.08.004

Goldman, N., Chen, M., Fujita, T., Xu, Q., Peng, W., Liu, W., et al. (2010). Adenosine Al receptors mediate local anti-nociceptive effects of acupuncture. Nat. Neurosci. 13, 883-888. doi: 10.1038/nn.2562

Gondim, D. V., Araujo, J. C., Cavalcante, A. L., Havt, A., Quetz, J. S., Brito, G. A., et al. (2012). CB1 and CB2 contribute to antinociceptive and antiinflammatory effects of electroacupuncture on experimental arthritis of the 
rat temporomandibular joint. Can. J. Physiol. Pharmacol. 90, 1479-1489. doi: 10.1139/y2012-130

Grillo, C. M., Wada, R. S., da Luz, Rosário, and de Sousa, M. (2014). Acupuncture in the management of acute dental pain. J. Acupunct. Meridian Stud. 7, 65-70. doi: 10.1016/j.jams.2013.03.005

Haake, M., Müller, H. H., Schade-Brittinger, C., Basler, H. D., Schäfer, H., Maier, C., et al. (2007). German acupuncture trials (GERAC) for chronic low back pain: randomized, multicenter, blinded, parallel-group trial with 3 groups. Arch. Intern. Med. 167, 1892-1898. doi: 10.1001/archinte.167.17.1892

Han, J. S. (2004). Acupuncture and endorphins. Neurosci. Lett. 361, 258-261. doi: 10.1016/j.neulet.2003.12.019

Han, J. S. (2011). Acupuncture analgesia: areas of consensus and controversy. Pain 152 (3 Suppl.), S41-S48.

Harte, S. E., Harris, R. E., and Clauw, D. J. (2018). The neurobiology of central sensitization. J. Appl. Biobehav. Res. 23:e12137.

He, D., Veiersted, K. B., Høstmark, A. T., and Medbø, J. I. (2004). Effect of acupuncture treatment on chronic neck and shoulder pain in sedentary female workers: a 6-month and 3-year follow-up study. Pain 109, 299-307. doi: 10. 1016/s0304-3959(04)00049-1

Hesselink, J. M., and Kopsky, D. J. (2011). Enhancing acupuncture by low dose naltrexone. Acupunct. Med. 29, 127-130. doi: 10.1136/aim.2010.003566

Ho, Y. C., Lee, H. J., Tung, L. W., Liao, Y. Y., Fu, S. Y., Teng, S. F., et al. (2011). Activation of orexin 1 receptors in the periaqueductal gray of male rats leads to antinociception via retrograde endocannabinoid (2-arachidonoylglycerol)induced disinhibition. J. Neurosci. 31, 14600-14610. doi: 10.1523/jneurosci. 2671-11.2011

Kano, M. (2014). Control of synaptic function by endocannabinoid-mediated retrograde signaling. Proc. Jpn. Acad. Ser. B Phys. Biol. Sci. 90, 235-250. doi: 10.2183/pjab.90.235

Kasper, A. M., Ridpath, A. D., Arnold, J. K., Chatham-Stephens, K., Morrison, M., Olayinka, O., et al. (2015). Severe illness associated with reported use of synthetic cannabinoids - mississippi, april 2015. MMWR Morb. Mortal. Wkly. Rep. 64, 1121-1122. doi: 10.15585/mmwr.mm6439a7

Khan, N., Halim, S. A., Khan, W., Zafar, S. K., and Ul-Haq, Z. (2019). In-silico designing and characterization of binding modes of two novel inhibitors for CB1 receptor against obesity by classical 3D-QSAR approach. J. Mol. Graph. Model. 89, 199-214. doi: 10.1016/j.jmgm.2019.03.016

Khan, S. P., Pickens, T. A., and Berlau, D. J. (2019). Perspectives on cannabis as a substitute for opioid analgesics. Pain Manag .9, 191-203. doi: 10.2217/pmt2018-0051

Kim, J. H., Min, B. I., Schmidt, D., Lee, H. J., and Park, D. S. (2000). The difference between electroacupuncture only and electroacupuncture with manipulation on analgesia in rats. Neurosci. Lett. 279, 149-152. doi: 10.1016/s0304-3940(99) 00994-5

Kiser, R. S., Khatami, M. J., Gatchel, R. J., Huang, X. Y., Bhatia, K., and Altshuler, K. Z. (1983). Acupuncture relief of chronic pain syndrome correlates with increased plasma met-enkephalin concentrations. Lancet 2, 1394-1396. doi: 10.1016/s0140-6736(83)90925-x

Kong, J., Ma, L., Gollub, R. L., Wei, J., Yang, X., Li, D., et al. (2002). A pilot study of functional magnetic resonance imaging of the brain during manual and electroacupuncture stimulation of acupuncture point (LI-4 Hegu) in normal subjects reveals differential brain activation between methods. J. Altern. Complement. Med. 8, 411-419. doi: 10.1089/107555302760253603

Lai, H. C., Lin, Y. W., and Hsieh, C. L. (2019). Acupuncture-analgesia-mediated alleviation of central sensitization. Evid. Based Complement. Alternat. Med. 2019:6173412.

Lee, I. S., Lee, S. H., Kim, S. Y., Lee, H., Park, H. J., and Chae, Y. (2013). Visualization of the meridian system based on biomedical information about acupuncture treatment. Evid. Based Complement. Alternat. Med. 2013:872142.

Lee, M. T., Chen, Y. H., Mackie, K., and Chiou, L. C. (2020). Median nerve stimulation as a nonpharmacological approach to bypass analgesic tolerance to morphine: a proof-of-concept study in mice. J Pain. S1526-5900, 30084-30085.

Li, J., Li, J., Chen, Z., Liang, F., Wu, S., and Wang, H. (2012). The influence of PC6 on cardiovascular disorders: a review of central neural mechanisms. Acupunct. Med. 30, 47-50. doi: 10.1136/acupmed-2011-010060

Lin, X., Huang, K., Zhu, G., Huang, Z., Qin, A., and Fan, S. (2016). The effects of acupuncture on chronic knee pain due to osteoarthritis: a meta-analysis. J. Bone. Joint. Surg. Am. 98, 1578-1585. doi: 10.2106/jbjs.15.00620
Linde, K., Allais, G., Brinkhaus, B., Fei, Y., Mehring, M., Vertosick, E. A., et al. (2016). Acupuncture for the prevention of episodic migraine. Cochrane Database Syst. Rev. 6:CD001218.

Liu, X. L., Tan, J. Y., Molassiotis, A., Suen, L. K., and Shi, Y. (2015). Acupuncturepoint stimulation for postoperative pain control: a systematic review and metaanalysis of randomized controlled trials. Evid. Based Complement. Alternat. Med. 2015:657809.

Loeser, J. D., and Melzack, R. (1999). Pain: an overview. Lancet 353, 1607-1609.

Lv, Q., Wu, F., Gan, X., Yang, X., Zhou, L., Chen, J., et al. (2019). The involvement of descending pain inhibitory system in electroacupuncture-induced analgesia. Front. Integr. Neurosci. 13:38.

Maccarrone, M. (2017). Metabolism of the endocannabinoid anandamide: open questions after 25 years. Front. Mol. Neurosci. 10:166.

Manheimer, E., Cheng, K., Linde, K., Lao, L., Yoo, J., Wieland, S., et al. (2010). Acupuncture for peripheral joint osteoarthritis. Cochrane Database Syst. Rev. 1:CD001977.

Mayer, D. J., Price, D. D., and Rafii, A. (1977). Antagonism of acupuncture analgesia in man by the narcotic antagonist naloxone. Brain Res. 121, 368-372. doi: 10.1016/0006-8993(77)90161-5

McNaull, B., Trang, T., Sutak, M., and Jhamandas, K. (2007). Inhibition of tolerance to spinal morphine antinociception by low doses of opioid receptor antagonists. Eur. J. Pharmacol. 560, 132-141. doi: 10.1016/j.ejphar.2006.12.013

McPartland, J. M., Norris, R. W., and Kilpatrick, C. W. (2007). Coevolution between cannabinoid receptors and endocannabinoid ligands. Gene 397, 126135. doi: 10.1016/j.gene.2007.04.017

Micale, V., Drago, F., Noerregaard, P. K., Elling, C. E., and Wotjak, C. T. (2019). The Cannabinoid CB1 Antagonist TM38837 with limited penetrance to the brain shows reduced fear-promoting effects in mice. Front. Pharmacol. 10:207.

Mist, S. D., and Jones, K. D. (2018). Randomized controlled trial of acupuncture for women with fibromyalgia: group acupuncture with traditional chinese medicine diagnosis-based point selection. Pain Med. 19, 1862-1871. doi: 10. $1093 / \mathrm{pm} / \mathrm{pnx} 322$

Musial, F. (2019). Acupuncture for the treatment of pain - a mega-placebo? Front. Neurosci. 13:1110.

Musil, F., Pokladnikova, J., Pavelek, Z., Wang, B., Guan, X., and Valis, M. (2018). Acupuncture in migraine prophylaxis in Czech patients: an open-label randomized controlled trial. Neuropsychiatr. Dis. Treat 14, 1221-1228. doi: 10.2147/ndt.s155119

Napadow, V., Makris, N., Liu, J., Kettner, N. W., Kwong, K. K., and Hui, K. K. (2005). Effects of electroacupuncture versus manual acupuncture on the human brain as measured by fMRI. Hum. Brain Mapp. 24, 193-205. doi: 10.1002/hbm. 20081

Ng, M. M., Leung, M. C., and Poon, D. M. (2003). The effects of electroacupuncture and transcutaneous electrical nerve stimulation on patients with painful osteoarthritic knees: a randomized controlled trial with followup evaluation. J. Altern. Complement. Med. 9, 641-649. doi: 10.1089/ 107555303322524490

Pacheco, D., Klein, A., de Castro Perez, A., da Fonseca, Pacheco, C. M., de Francischi, J. N., et al. (2008). The mu-opioid receptor agonist morphine, but not agonists at delta- or kappa-opioid receptors, induces peripheral antinociception mediated by cannabinoid receptors. Br. J. Pharmacol. 154, 1143-1149. doi: 10.1038/bjp.2008.175

Pacheco, D., Klein, A., Perez, A. C., Pacheco, C. M., de Francischi, J. N., Reis, G. M., et al. (2009). Central antinociception induced by mu-opioid receptor agonist morphine, but not delta- or kappa-, is mediated by cannabinoid CB1 receptor. Br. J. Pharmacol. 158, 225-231. doi: 10.1111/j.1476-5381.2009. 00310.x

Pagotto, U., Marsicano, G., Cota, D., Lutz, B., and Pasquali, R. (2006). The emerging role of the endocannabinoid system in endocrine regulation and energy balance. Endocr. Rev. 27, 73-100. doi: 10.1210/er.2005-0009

Palazzo, E., Luongo, L., Novellis, V., Rossi, F., and Maione, S. (2010). The role of cannabinoid receptors in the descending modulation of pain. Pharmaceuticals 3, 2661-2673. doi: 10.3390/ph3082661

Paquette, J., and Olmstead, M. C. (2005). Ultra-low dose naltrexone enhances cannabinoid-induced antinociception. Behav. Pharmacol. 16, 597-603. doi: 10.1097/00008877-200512000-00001

Pavão, T. S., Vianna, P., Pillat, M. M., Machado, A. B., and Bauer, M. E. (2010). Acupuncture is effective to attenuate stress and stimulate lymphocyte 
proliferation in the elderly. Neurosci. Lett. 484, 47-50. doi: 10.1016/j.neulet. 2010.08.016

Pert, A., Dionne, R., Ng, L., Bragin, E., Moody, T. W., and Pert, C. B. (1981). Alterations in rat central nervous system endorphins following transauricular electroacupuncture. Brain Res. 224, 83-93. doi: 10.1016/0006-8993(81)91118-5

Pomeranz, B., and Chiu, D. (1976). Naloxone blockade of acupuncture analgesia: endorphin implicated. Life Sci. 19, 1757-1762. doi: 10.1016/0024-3205(76) 90084-9

Raffaeli, W., and Arnaudo, E. (2017). Pain as a disease: an overview. J. Pain Res. 10, 2003-2008. doi: 10.2147/jpr.s138864

Razavi, B. M., and Hosseinzadeh, H. (2017). A review of the role of orexin system in pain modulation. Biomed. Pharmacother. 90, 187-193. doi: 10.1016/j.biopha. 2017.03.053

Research Group of Acupuncture Anesthesia (1973). Effect of acupuncture on the pain threshold of human skin. Chin. Med. J. 3, 35-37.

Sarchielli, P., Pini, L. A., Coppola, F., Rossi, C., Baldi, A., Mancini, M. L., et al. (2007). Endocannabinoids in chronic migraine: CSF findings suggest a system failure. Neuropsychopharmacology 32, 1384-1390. doi: 10.1038/sj.npp.1301246

Scharf, H. P., Mansmann, U., Streitberger, K., Witte, S., Krämer, J., Maier, C., et al. (2006). Acupuncture and knee osteoarthritis: a three-armed randomized trial. Ann. Intern. Med. 145, 12-20. doi: 10.7326/0003-4819-145-1-20060704000005

Selfe, T. K., and Taylor, A. G. (2008). Acupuncture and osteoarthritis of the knee: a review of randomized, controlled trials. Fam. Community Health 31, 247-254. doi: 10.1097/01.fch.0000324482.78577.0f

Shao, X. M., Shen, Z., Sun, J., Fang, F., Fang, J. F., Wu, Y. Y., et al. (2015). Strong manual acupuncture stimulation of "Huantiao" (GB 30) reduces pain-induced anxiety and p-erk in the anterior cingulate cortex in a rat model of neuropathic pain. Evid. Based Complement. Alternat. Med. 2015:235491.

Sharma, M. K., Murumkar, P. R., Barmade, M. A., Giridhar, R., and Yadav, M. R. (2015). A comprehensive patents review on cannabinoid 1 receptor antagonists as antiobesity agents. Expert Opin. Ther. Pat. 25, 1093-1116. doi: 10.1517/ 13543776.2015.1064898

Shen, Y. F., Younger, J., Goddard, G., and Mackey, S. (2009). Randomized clinical trial of acupuncture for myofascial pain of the jaw muscles. J. Orofac. Pain 23, 353-359.

Shiro, Y., Arai, Y. C., Ikemoto, T., Kawai, T., Ikeuchi, M., and Ushida, T. (2014). Distal traditional acupuncture points of the large intestinal meridian and the stomach meridian differently affect heart rate variability and oxygenation of the trapezius muscle. Evid. Based Complement. Alternat. Med. 2014:283010.

Shou, Y., Yang, Y., Xu, M. S., Zhao, Y. Q., Ge, L. B., and Zhang, B. M. (2013). Electroacupuncture inhibition of hyperalgesia in rats with adjuvant arthritis: involvement of cannabinoid receptor 1 and dopamine receptor subtypes in striatum. Evid. Based Complement. Alternat. Med. 2013:393460.

Sidhu, A., Murgahayah, T., Narayanan, V., Chandran, H., and Waran, V. (2017). Electroacupuncture-assisted craniotomy on an awake patient. J. Acupunct. Meridian Stud. 10, 45-48. doi: 10.1016/j.jams.2016.06.005

Stampanoni Bassi, M., Gilio, L., Maffei, P., Dolcetti, E., Bruno, A., Buttari, F., et al. (2018). Exploiting the multifaceted effects of cannabinoids on mood to boost their therapeutic use against anxiety and depression. Front. Mol. Neurosci. 11:424.

Stasiulewicz, A., Znajdek, K., Grudzień, M., Pawiński, T., and Sulkowska, A. J. I. (2020). A Guide to targeting the endocannabinoid system in drug design. Int. J. Mol. Sci. 21:2778. doi: 10.3390/ijms21082778

Su, T. F., Zhang, L. H., Peng, M., Wu, C. H., Pan, W., Tian, B., et al. (2011). Cannabinoid CB2 receptors contribute to upregulation of beta-endorphin in inflamed skin tissues by electroacupuncture. Mol. Pain 7:98.

Su, T. F., Zhao, Y. Q., Zhang, L. H., Peng, M., Wu, C. H., Pei, L., et al. (2012). Electroacupuncture reduces the expression of proinflammatory cytokines in inflamed skin tissues through activation of cannabinoid CB2 receptors. Eur. J. Pain 16, 624-635. doi: 10.1002/j.1532-2149.2011.00055.x

Sun, Z. G., Pi, Y. L., Zhang, J., Wang, M., Zou, J., and Wu, W. (2019). Effect of acupuncture at ST36 on motor cortical excitation and inhibition. Brain Behav. 9:e01370.

Toth, K. F., Adam, D., Biro, T., and Olah, A. (2019). Cannabinoid signaling in the skin: therapeutic potential of the "C(ut)annabinoid" system. Molecules 24:918. doi: 10.3390/molecules 24050918
Vickers, A. J., Cronin, A. M., Maschino, A. C., Lewith, G., MacPherson, H., Foster, N. E., et al. (2012). Acupuncture for chronic pain: individual patient data metaanalysis. Arch. Intern. Med. 172, 1444-1453. doi: 10.1001/archinternmed.2012. 3654

Vickers, A. J., Vertosick, E. A., Lewith, G., MacPherson, H., Foster, N. E., Sherman, K. J., et al. (2018). Acupuncture for chronic pain: update of an individual patient data meta-analysis. J. Pain 19, 455-474. doi: 10.1016/j.jpain.2017.11.005

Wan, Y., Wilson, S. G., Han, J., and Mogil, J. S. (2001). The effect of genotype on sensitivity to electroacupuncture analgesia. Pain 91, 5-13. doi: 10.1016/s03043959(00)00416-4

Wang, H., Xie, H., and Dey, S. K. (2006). Endocannabinoid signaling directs periimplantation events. AAPS J. 8, E425-E432. doi: 10.1007/bf02854916

Wang, Y., Xue, C. C., Helme, R., Da Costa, C., and Zheng, Z. (2015). Acupuncture for frequent migraine: a randomized, patient/assessor blinded, controlled trial with one-year follow-up. Evid. Based Complement. Alternat. Med. 2015:920353.

Webster, L. R. (2007). Oxytrex: an oxycodone and ultra-low-dose naltrexone formulation. Expert Opin. Investig. Drugs 16, 1277-1283. doi: 10.1517/ 13543784.16.8.1277

White, A., Cummings, M., and Filshie, J. (eds) (2008). "Effective needling techniques," in an Introduction to Western Medical Acupuncture, eds M. Cummings, J. Filshie, and A. White (London: Churchill Livingstone).

Xie, Y. H., Chai, X. Q., Wang, Y. L., Gao, Y. C., and Ma, J. (2014). Effect of electroacupuncture stimulation of Ximen (PC4) and Neiguan (PC6) on remifentanilinduced breakthrough pain following thoracal esophagectomy. J. Huazhong Univ. Sci. Technolog. Med. Sci. 34, 569-574. doi: 10.1007/s11596-014-1317-x

Yadav, M. R., and Murumkar, P. R. (2018). Advances in patented CB1 receptor antagonists for obesity. Pharm. Pat. Anal. 7, 169-173. doi: 10.4155/ppa-20180020

Yang, J., Zeng, F., Feng, Y., Fang, L., Qin, W., Liu, X., et al. (2012). A PET-CT study on the specificity of acupoints through acupuncture treatment in migraine patients. BMC Complement. Altern. Med. 12:123.

Yang, Y., Ji, L., Li, G., Deng, X., Cai, P., and Guan, L. (2012). Differences in thermal effects of moxibustion at zusanli (ST 36) and hegu (LI 4) on various facial areas in healthy people. J. Tradit. Chin. Med. 32, 397-403. doi: 10.1016/s02546272(13)60045-x

Yen, C. M., Wu, T. C., Hsieh, C. L., Huang, Y. W., and Lin, Y. W. (2019). Distal electroacupuncture at the LI4 acupoint reduces CFA-induced inflammatory pain via the brain TRPV1 signaling pathway. Int. J. Mol. Sci. 20:4471. doi: 10.3390/ijms20184471

Yeo, S., Choe, I. H., van den Noort, M., Bosch, P., Jahng, G. H., Rosen, B., et al (2014). Acupuncture on GB34 activates the precentral gyrus and prefrontal cortex in Parkinson's disease. BMC Complement. Altern. Med. 14:336.

Yuan, J., Purepong, N., Kerr, D. P., Park, J., Bradbury, I., and McDonough, S. (2008). Effectiveness of acupuncture for low back pain: a systematic review. Spine (Phila Pa 1976) 33, E887-E900. doi: 10.1136/acupmed-2013-010385

Yuan, X. C., Wang, Q., Su, W., Li, H. P., Wu, C. H., Gao, F., et al. (2018a). Electroacupuncture potentiates peripheral CB2 receptor-inhibited chronic pain in a mouse model of knee osteoarthritis. J. Pain Res. 11, 2797-2808. doi: 10.2147/jpr.s171664

Yuan, X. C., Zhu, B., Jing, X. H., Xiong, L. Z., Wu, C. H., Gao, F., et al. (2018b) Electroacupuncture potentiates cannabinoid receptor-mediated descending inhibitory control in a mouse model of knee osteoarthritis. Front. Mol. Neurosci. $11: 112$.

Zhang, H., He, S., Hu, Y., and Zheng, H. (2016). Antagonism of cannabinoid receptor 1 attenuates the anti-inflammatory effects of electroacupuncture in a rodent model of migraine. Acupunct. Med. 34, 463-470. doi: 10.1136/acupmed2016-011113

Zhang, J., Chen, L., Su, T., Cao, F., Meng, X., Pei, L., et al. (2010). Electroacupuncture increases CB2 receptor expression on keratinocytes and infiltrating inflammatory cells in inflamed skin tissues of rats. J. Pain 11, 1250-1258. doi: 10.1016/j.jpain.2010.02.013

Zhang, R., Lao, L., Ren, K., and Berman, B. M. (2014). Mechanisms of acupunctureelectroacupuncture on persistent pain. Anesthesiology 120, 482-503. doi: 10 . 1097/aln.0000000000000101

Zhang, Z. J., Wang, X. M., and McAlonan, G. M. (2012). Neural acupuncture unit: a new concept for interpreting effects and mechanisms of acupuncture. Evid. Based Complement. Alternat. Med. 2012:429412. 
Zhao, C. H., Stillman, M. J., and Rozen, T. D. (2005). Traditional and evidence-based acupuncture in headache management: theory, mechanism, and practice. Headache 45, 716-730. doi: 10.1111/j.1526-4610.2005. 05139.x

Zhao, L., Chen, J., Liu, C. Z., Li, Y., Cai, D. J., Tang, Y., et al. (2012). A review of acupoint specificity research in china: status quo and prospects. Evid. Based Complement. Alternat. Med. 2012:543943.

Zhao, Z. Q. (2008). Neural mechanism underlying acupuncture analgesia. Prog. Neurobiol. 85, 355-375. doi: 10.1016/j.pneurobio.2008.05.004

Zhu, H., Xiang, H. C., Li, H. P., Lin, L. X., Hu, X. F., Zhang, H., et al. (2019). Inhibition of GABAergic neurons and excitation of glutamatergic neurons in the ventrolateral periaqueductal gray participate in electroacupuncture analgesia mediated by cannabinoid receptor. Front. Neurosci. 13:484.
Zou, S., and Kumar, U. (2018). Cannabinoid receptors and the endocannabinoid system: signaling and function in the central nervous system. Int. J. Mol. Sci. 19:833. doi: $10.3390 /$ ijms 19030833

Conflict of Interest: The authors declare that the research was conducted in the absence of any commercial or financial relationships that could be construed as a potential conflict of interest.

Copyright (c) 2021 MacDonald and Chen. This is an open-access article distributed under the terms of the Creative Commons Attribution License (CC BY). The use, distribution or reproduction in other forums is permitted, provided the original author(s) and the copyright owner(s) are credited and that the original publication in this journal is cited, in accordance with accepted academic practice. No use, distribution or reproduction is permitted which does not comply with these terms. 